Earth \& Environment | Noélie Bontemps

\title{
Slip sliding away
}

Landslides, earthquakes, rainfall and the Andes

Landslides are the most deadly secondary effect of earthquak in mountainous regions. Dr Grenoble Alpes) has uncovered the secrets of a slow landside in Penn by monitoring post-seismic dry and wet seasons. GPS and seismic data confirm that in combination, earthquakes and rainfall cause greater landslide motion than either force alone. There is a strong decrease in soil rigidity following earth and slowly in the wet season with soil rigidity a key factor in controlling landslide movement.

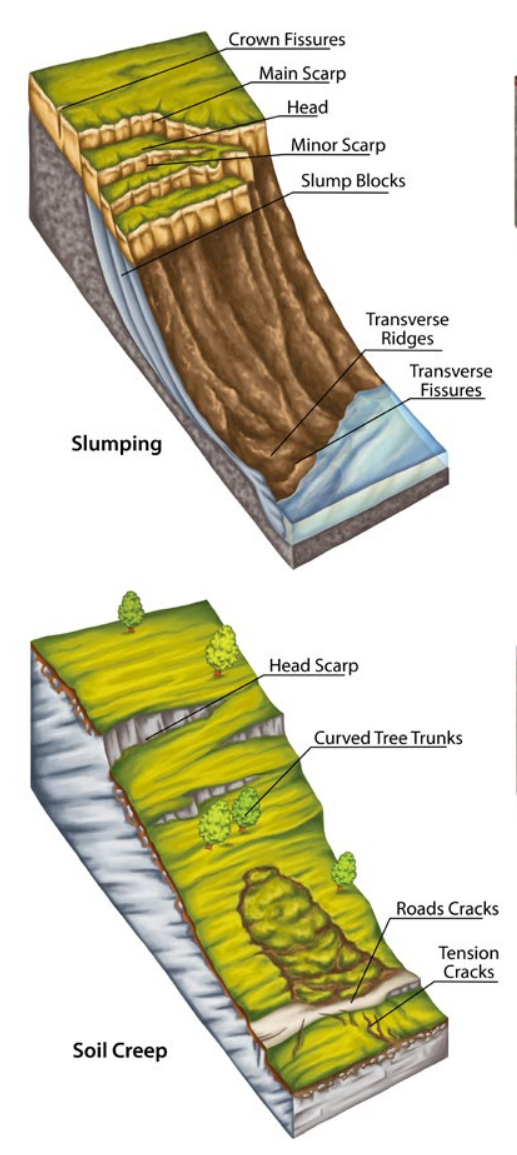

7 leadly secondary effect of earthquakes in mountainous areas. Despite this, the mechanisms behind landslide triggering remain poorly understood; nowhere is this truer than in regions where landslide kinematics are intricately linked to seismic activity and rainfall. Improved vital for effective hazard mangement and mitigation.

To tackle this gap in knowledge, a group of researchers has spent 10 years
building an international collaboration focused on a remote corner of South America. Scientists from the Institut de Recherche pour le Développement (IRD) in France, and those from

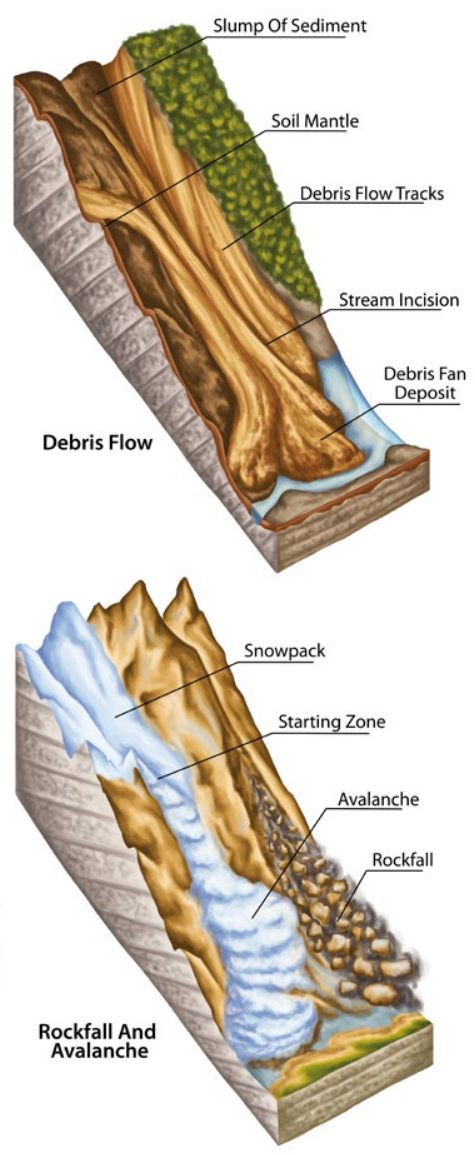

the Instituto Geologico Minero y Metalurgico (NGEMMET) in Peru have worked together in the high Andes to uncover the secrets of a persistent, slow Coride on the southern wall of Peru's Colca Valley.

Landslides are widely perceived as catastrophic events, to the casual of soil, rocks, and other debris hurtling downslope at speeds on the order of meters per second. However. slow landslides move at a fraction of this speed, creeping downslope at just millimetres to meters per year, with some persisting for decades or longer. Unless transitioning to rapid flow through catastrophic failure, such events tend not to pose a threat to life; however, they are major drivers of morphological change, sometimes on a landscape-scale, and can cause extensive damage to property and infrastructure.

From a research perspective, such events offer scientists a window into monitoring. The slow-moving Maca landslide in Peru provides a particularly useful research focus because, owing to its geographical position its development is strongly related to both seasonal rainfall and high regional seismicity, with opportunities to investigate the individual and combined impacts of these factors. Initiated and led by Pascal Lacroix (IRD) and Eric Larose (CNRS), this collaborative experiment between a Peruvian institution, the French academy, and the approval of the local population has won financial support from the Society of Exploration Geophysicists the European Space Agency (ESA) the the European Space Agency (ESA), the
Centre National D'Etudes Spatiales

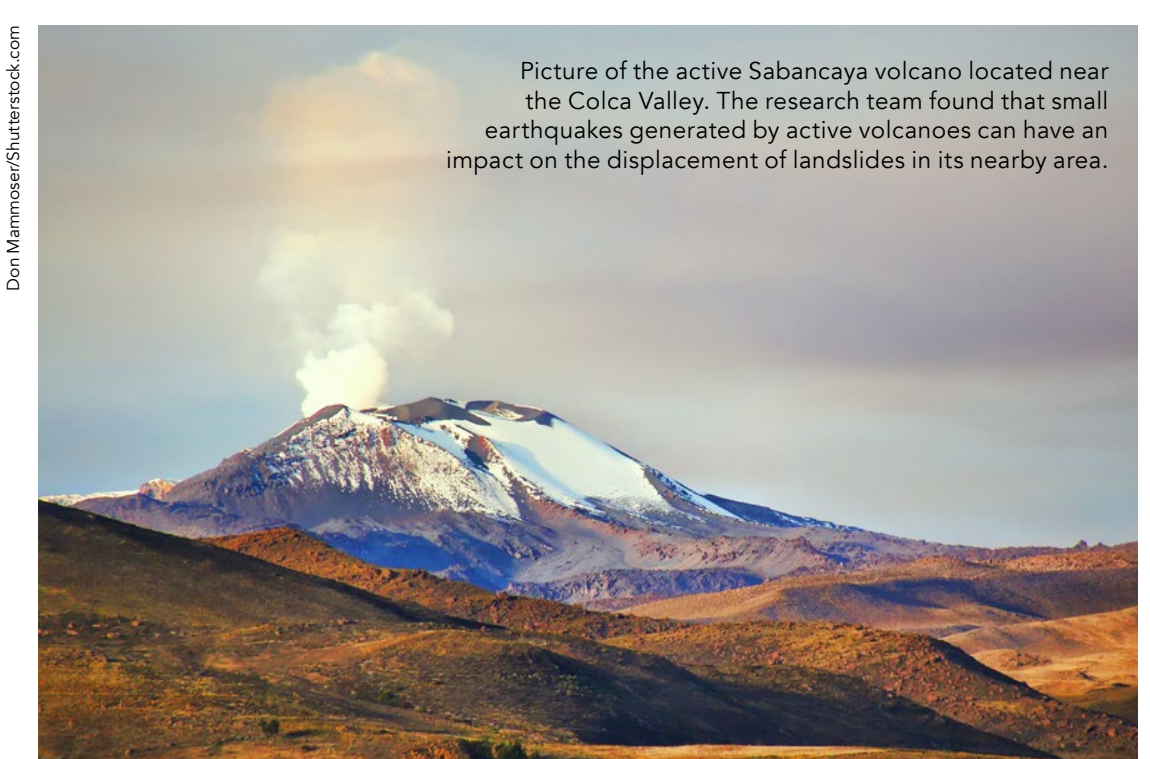

(CNES), and the Institut National addition, the work of No B B . In was possible thanks to the financing of her PhD by the Labex OSUG@2020 and the Centre National D'Etudes Spatiales (CNES).

The Andes mountain chain, running $7000 \mathrm{~km}$ South America and reaching an

elevation of more than $6000 \mathrm{~m}$, is the result of plate tectonics. The subduction of the Nazca under the South American plates has resulted in uplift, crustal

\section{A LANDSCAPE OF FIRE AND WATER thickening, volcanic activity, and}

May. As such, Dr Bontemps and her colleagues were able to monitor arthquakes during both the dy and wet seasons, allowing for detailed analysis of the individual and combined impacts of earthquakes and rainfall on slow-moving landslides.

MEASURING THE MACA LANDSLID The broad ( $1 \mathrm{~km}$ wide) Maca landslide involves the slow-to-very slow slippage of clay and silt (annual mean of $1.5 \mathrm{~m} /$ yr, although it may reach up to $7 \mathrm{~m} /$ year during particularly wet rainy years). The flow is maintained by river-erosion of the forward end, although both rainfall and moderate regional earthquakes ( $M w \leq 6)$ accelerate the motion temporarily. The volume of materialis approxmately 60 $50 \mathrm{~m}$ of lacustrine (lake) deposits, while the upper 8-12 $m$ is a permeable ayer of material formed by a debris avalanche some 10,000 years ago. Overall, the landslide can be considered typical of events that occur under similar geological and morphological The Colca Valley extends some $70 \mathrm{~km}$ through the Peruvian Andes. With depths more than 10,700

feet), it is one of the deepest canyons widespread seismic activity. The Colca in the world, eclipsing the more famous Grand Canyon, at just $\sim 1800 \mathrm{~m}$ (or 6000 feet) depth. The Valley has a rich social and cultural history, stretching back though in to the prelnca era, Saby Sabancaya Volcano, and is impacted by seismicity related to both local Precipitation in the valley is highly Precipitation in the valley is highy occurring between Decenter and such, it has been comprehensively monitored over the
Dr Bontemps and her colleagues have ground) and geodetic (i.e., deformation ladslide. They have used the Globat Positioning System (GPS) to mose the displacement of the landslide focused on 3 years of data from seismic (i.e., waves of energy traveling in the

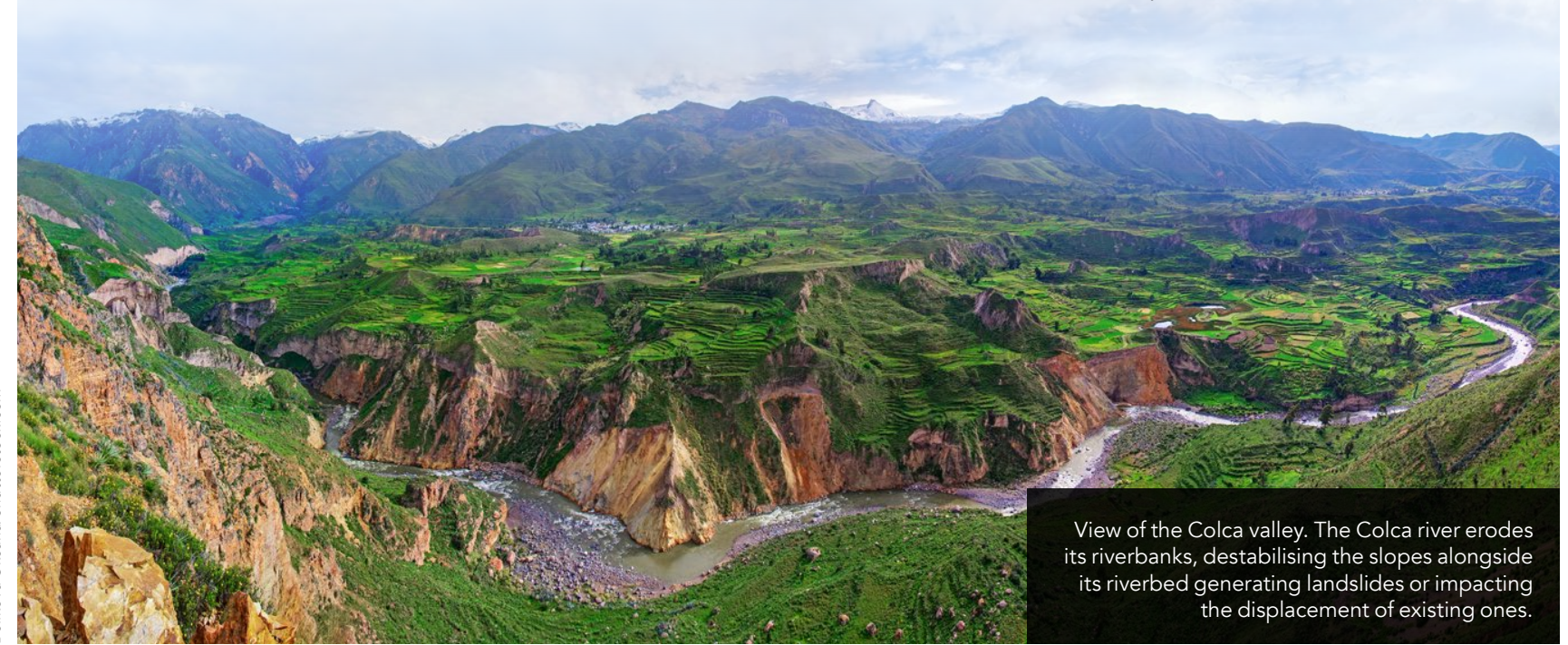


and a meteorological station to track rainfall. A soismometer has been used measure variations in the rigidity and density of the soil using a technique called ambient noise correlation. Ambient noise correlation, sometim called passive seismic interferometry is a cutting edge method that was first used for landslide monitoring in 2012 following observations of changing soil rigidity 5 days before a catastrophic landslide in Switzerland; to date, nine landslides have been monitored using this approach worldwide.

Ambient noise correlation reconstructs the response of the landslide material to excitation (e.g., an earthquake) by cross-correlating the velocity of seismic in Maca, a menu dis by vehicles on the nearby road, by the river at the toe of the landlide, and by wind The changing seismic velocity can correlate with the decrease of rigidity of the material within the landslide and such, offers the potential for real-time

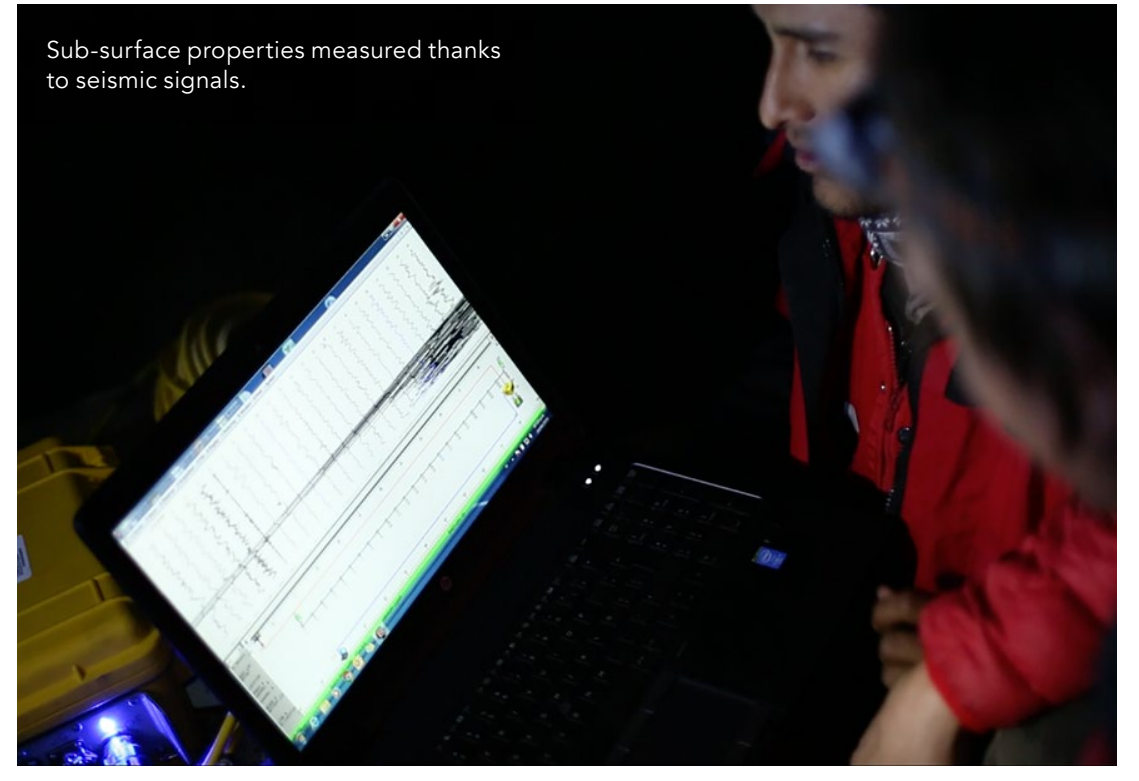

rainy season and the other during opportun for comparison.

\section{NEW INSIGHTS INTO}

\section{LANDSLIDE MECHANISMS}

The study at Maca yields a wealth of new prediction. cause greater landslide motion than either force alone.

AtMaca, the

installed in early 2016; in the same year, two earthquakes of similar magnitude (Mw 5 and 5.5) occurred at similar One earthquake struck during the

in particular, the GPS results confirm that in combination, earthquakes and rainfal cause greater landslide motion than either decrease in the rigidity of the soil (i.e,

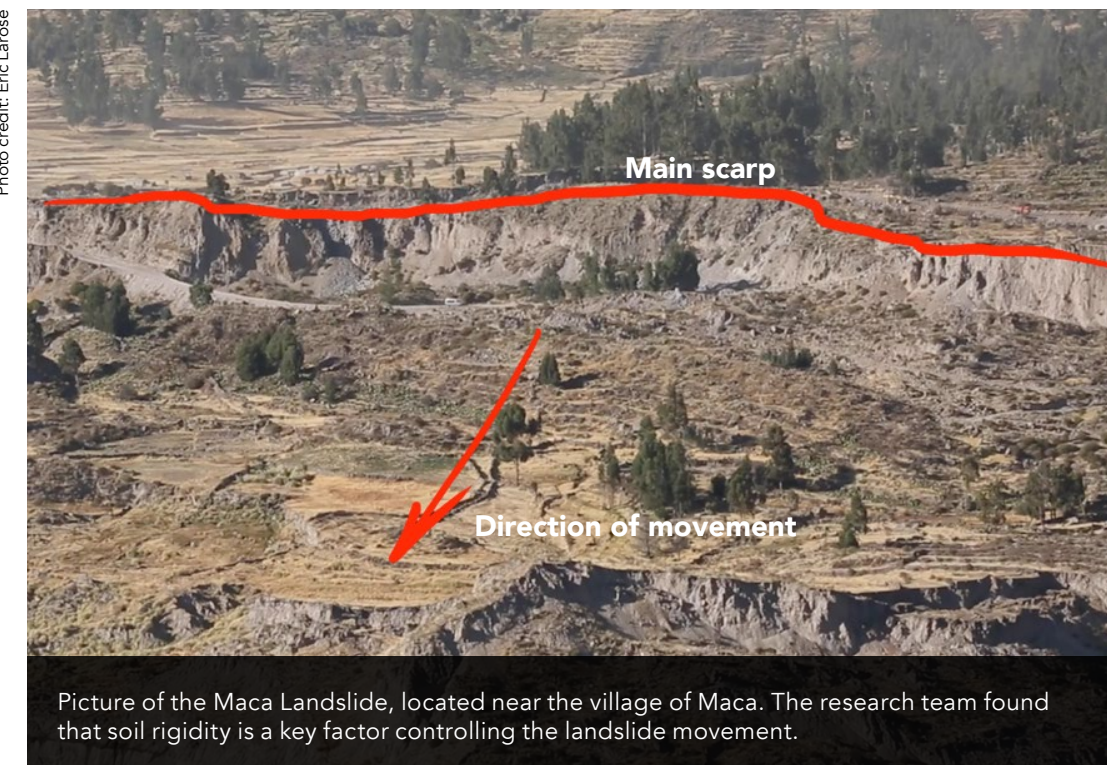
was below a certain threshold (i.e., the

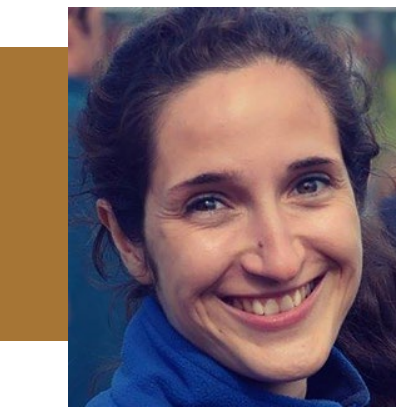

\section{Behind the Research}

\section{Dr Noélie Bontemps}

E: noelie.bontemps@univ-grenoble-alpes.fr W: https://www.univ-grenoble-alpes.fr/noelie both $\mathrm{Mw} \sim 5$ earthquakes.

During the dry season, rigidity recovered rapidly after the earthquake; However, during the wet season, both subsequent small earthquakes ( $\mathrm{Mw}<3.6)$ and rainfall inhibited the post-seismic recovery of

Research Objectives

The research of Noélie Bontemps aims to understand all the mechanisms behind landslide triggering, especially in regions where earthquake and precipitations can combine to impact a landslides kinematic.

\section{Detail}

Noélie Bontemps

Université Grenoble Alpes

1381 rue de la piscin

Bio

Noélie Bontemps started to study the combined effect of earthquakes and precipitation on landslides during her decided to do a Ph.D. on the same subject. She obtained it in December 2019 at the University Grenoble Alpes (France)

\section{Funding} decrease following the earthquake, taking several

months to recover is pre seismic leve. Dr Bontemps and her colleagues suggest that the shaking generated the landslide mass. Rainfall is able to penetrate these cracks and prove to from healing In a similar vein, numerous small earthquakes also work to keep cracks open.

The team found that soil rigidity is a key factor in controlling the landslide movement. When the rigidity of the soil soil was either filled with water and/or cracked and damaged), the landslide above the threshold, the landslide slowed and sometimes stopped. These results provide new insights that will allow scientists and civil protection authorities to beter monitor and manage slowlandslide behaviour around the world pacticuly for landslides triggered by from optical Images time-Series" (ESA 15/P26), a CNES/ was in motion; when the rigidity was his experiment was funded by an SEG Geophysicists Without Borders grant, a grant from ESA through the Alcantara project "Monitoring and Detection of Landslides TOSCA grant, and a CNRS/NSU grant. The work of OSU Bo2 20 ros was supported by a grant from Labex 作 and a CNES doctoral fellowship.

\section{Collaborators}

consequence of a 10-year active collaboration between two public research organisations in France and Peru (INGEMMET and IRD) - Co-authors: Pascal Lacroix, Eric Larose, Edu Taipe,

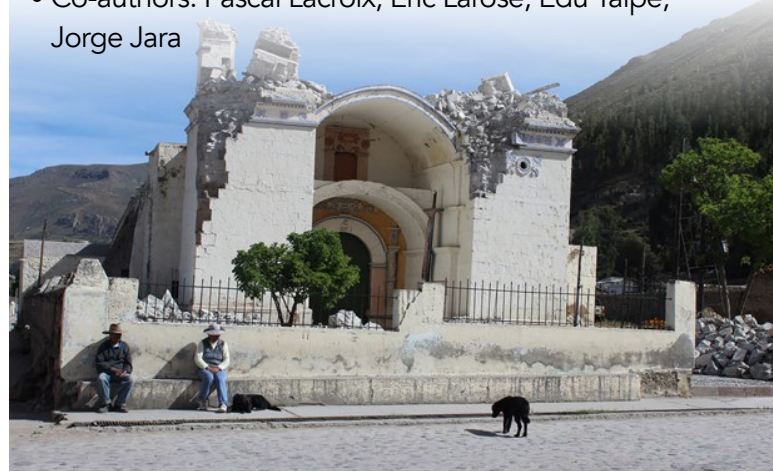

Ichupampa church, just $10 \mathrm{~km}$ from Maca, was destroyed by a
References

- Bontemps N, Lacroix P, Larose E, Jara J, Taipe E. (2020). Rain and small earthquakes maintain a slowmoving landslide in a persistent critical state. Nature Communications, 11, 780. https://doi.org/10.1038/ s41467-020-14445-3

- Lacroix P, Handwerger A, Bièvre G. (2020). Life and death of slow-moving landslides. Nature Reviews Earth \& Environment, 1, 404-419

- Mainsant G, Larose E, Brönniman C, Jongmans D, Michoud C, Jaboyedoff M. (2012). Ambient seismic noise Journal of Gephysical Research Earth Surface, 17, F1. https://doi.org/10.1029/2011JF002159

- Le Breton M, Bontemps N, Guillemot A, Baillet L, - Bare E. (Under review). Landslide Monitoring Using Seismic Ambient Noise Correlation: Challenges and Applications

\section{Personal Response}

Can your findings be extended to rapid landslides or do they operate under different mechanisms?

IV This is an important question as rapid landslides are slow-moving landslides can ar cos suddesly turn into ress, ones. The mechanisms that we observe here thus do app to rapid landslides. Studying slow-moving landslides such as the one we monitored in Maca is therefore important, not only for improving our understanding on landslides, small-time scale (a few minutes down to a few seconds). Despite this, the technique does still apply to rapid landslides, especially for quantifying the recovery, and

\section{Can any of the changes in the Maca landslide} over time be linked to volcanic activity at nearby

\section{Sabancaya Volcano?}

II Yes, we saw that small magnitude earthquakes have 列

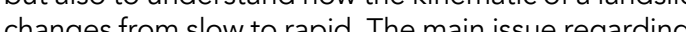
rapid landslides is their monitoring The seismic velocity changes, for example, are hardly observable on a very after a certain period of recovery. related to the Sabancaya volcano activity.
relat 